\title{
EXPERIMENTAL OBSERVATIONS ON THE THERMAL DEGRADATION OF A POROUS BED OF TIRES
}

\author{
Jean-Pierre Vantelon*, Bénigne Lodeho*, Stephane Pignoux*, Janet L. Ellzey** and José \\ L. Torero*** \\ *Laboratoire de Combustion et Detonique \\ ENSMA-Université de Poitiers, Poitiers, France \\ **Department of Mechanical Engineering \\ University of Texas, Austin, Texas, USA \\ ***School of Engineering and Electronics \\ The University of Edinburgh, Edinburgh, UK
}

\section{Corresponding Author:}

Jose L. Torero

School of Engineering and Electronics

King's Buildings

The University of Edinburgh

Edinburgh, EH9 3JN

United Kingdom

Fax: 44-131-650-5736

e-mail: J.Torero@ed.ac.uk

Colloquium: [9] Power Systems and Environmental Mitigation

Short Running Title: Thermal Degradation of Tires

\section{Word Count:}

Main Text

Equations

$$
(1)=23+(2)=23+(3)=31=
$$

References

$$
(9+2) * 2.3 * 7.6=
$$

Figure 1: $[7+(12 / 15) * 67] * 2.2+6$

Figure 3: $[7+(9 / 14) * 67] * 2.2+47 \quad 157$

Figure 4: $[7+(8 / 14) * 67] * 2.2+23 \quad 123$

Figure 5: $[7+(7 / 12) * 67] * 2.2+12 \quad 114$

Figure 6: $[7+(7 / 12) * 67] * 2.2+21$

Figure $7:[7+(7 / 12) * 67] * 2.2+18 \quad 149$

Figure 8: $[7+(7 / 12) * 67] * 2.2+22 \quad 124$

Figure 9: $[7+(7 / 12) * 67] * 2.2+21$

Figure 10: $[7+(8 / 12) * 67] * 2.2+30 \quad 144$

Total

5683

Abstract 


\begin{abstract}
In this paper, an experimental study on the forward combustion of a bed of tires and refractory briquettes is presented. Temperature measurements within the reactor were obtained as a function of time as well as the evolution of the fuel bed. The products of combustion were cooled down and usable liquid fuel was recovered and measured. The reaction was found to become unstable for fuel concentrations lower than $50 \%$. The results show that the airflow and tire concentration define different modes of combustion while the reaction remains oxygen limited. Oil production is maximized when an increase in airflow leads to a transition from a rate-limited reaction to a heat transfer-limited propagation. Variation of the tire concentration shows the importance of the inert in achieving high conversion rates.
\end{abstract}

\title{
Keywords
}

Incineration, thermal degradation, tires, real scale experiments 


\section{Introduction}

Despite efforts in recent years to protect the environment, the disposal of products at the end of their life remains a significant problem. The necessity of addressing this problem has been further emphasized by legislation that limits the disposal of any "recyclable goods". Only goods considered as having no value (“final waste”) will be stored awaiting an appropriate technical solution [1]. Therefore, it is clearly necessary to develop techniques for recycling valuable components of urban and industrial waste.

Today the difficulties encountered in treating certain goods are such that the economic and political considerations no longer determine the choice of the treatment process. The technical aspects regarding the energy requirements or the environmental impact have taken precedence [2]. The process must assure the transformation into usable materials or into energy while meeting standards on toxic emissions.

Much of the industrial and urban waste can be reused or recycled in various ways. But the disposal of tires presents a particularly challenging problem. In Europe, more than two million tons of tires are discarded every year most of which cannot be treated for reuse. Just in France, of the 400,000 tons per year of discarded tires 304,000 tons have to be considered as waste [3]. This does not take into account the tires that have been discarded and stored from previous years. The used tires are distributed among tire manufacturers and distributors (65\%), supermarkets (16\%), garages (14\%), and service stations (5\%) [4]. Since these sites are well identified, collection can be easily envisioned for a recycling program.

In recent years, several studies on thermal disposal of used tires have concluded that they can be recycled by utilization of either their energetic value or their material value [4]. The primary means of taking advantage of the energetic value of used tires is through incineration. Two main types of incinerators exist today: (1) bed incinerators (fixed bed or moving grates), in which a 
conventional combustible material such as oil or coal is replaced with tires either whole or shredded [5] (2) fluidized bed incinerator in which part of the traditional solid fuel is replaced with shredded tires. In both cases the treatment of the tires and pollutants as well as the recovery of the remnants pose significant problems that might render these processes uneconomical.

A promising alternative to these conventional incinerators is one in which the solid material smolders producing exhaust gases containing the vapors of combustible materials which are then condensed. In smoldering combustion, a relatively low temperature reaction front propagates through a porous fuel bed [6]. The properties of the porous material are important because heat is transferred from the post reaction zone to pre-reaction zone through solid phase conduction and solid to solid radiation. This has two major advantages, the preheating of the material in front of the reaction zone enhances the combustion process and the low temperatures of the smolder reaction generate the potential recovery of pyrolysis products. In this paper, we present results on this type of incinerator.

\section{Experimental Apparatus and Procedure}

The experimental apparatus (Fig. 1) consists of a reactor, two cooling towers, a fan, collection buckets, an after burner and post combustion chamber and the exhaust system. The entry chamber where the igniter torch is installed is $0.5 \mathrm{~m}$ in length. This chamber is separated from the main reactor by a perforated grill upon which the fuel bed rests. The main reactor is 0.5 $\mathrm{m}$ in diameter and $2 \mathrm{~m}$ in length. The two condensers $(0.25 \mathrm{~m} \mathrm{x} 2.8 \mathrm{~m})$ are in series with the fan. Remaining combustibles must pass through a flame in the post combustion chamber in order to ensure destruction of all toxic emissions.

Temperature measurements were made with type $\mathrm{K}$ (chromel-alumel) thermocouples of diameter $1.02 \mathrm{~mm}$ each. The thermocouple system in the main reactor consisted of 27 
thermocouples. Three sets of 8 thermocouples starting $100 \mathrm{~mm}$ above the grid and spaced 200 $\mathrm{mm}$ along the axial direction. The thermocouple sets where placed through the wall of the reactor $10 \mathrm{~mm}$ into the combustion chamber. Each set was spaced $120^{\circ}$ form each other. The final three thermocouples were placed on the axis of the reactor. These three thermocouples were placed at $100 \mathrm{~mm}, 200 \mathrm{~mm}$, and $300 \mathrm{~mm}$ from the grid. It was verified that the axial thermocouples only provided a slight shift upwards in the temperature $\left(<50^{\circ} \mathrm{C}\right)$. Additional temperature measurements were made at the center of the grid, at the exit of the main reactor, upstream of the first cooling tower, between the two cooling tower, downstream of the second cooling tower, upstream and downstream of the post combustion chamber, and in the exhaust system. Exhaust gas composition was determined to comply with environmental regulations. Concentrations of $\mathrm{NOx}, \mathrm{SO}_{2}, \mathrm{CO}$ were taken with a Testoterm (Testo 33) gas analyzer. Measurements were recorded throughout the entire duration of the experiments.

The fuel bed was a mixture of inert material and shredded tires. The inert material consisted of briquettes of refractory clay of approximately $4 \mathrm{~cm}$ in diameter. The density and specific heat of the material were $2205 \mathrm{~kg} / \mathrm{m}^{3}$ and $2165 \mathrm{~J} / \mathrm{kgK}$. The tires were automotive tires of various origins and were shredded into pieces that varied in diameter between 3 and $10 \mathrm{~cm}$. The steel belts were part of the shredded tire mixture. The density and specific heat of the tire material were $1037 \mathrm{~kg} / \mathrm{m}^{3}$ and $1770 \mathrm{~J} / \mathrm{kgK}$ respectively [4]. The composition of the tires was approximately $40 \%$ rubber, $28 \%$ carbon black, $18 \%$ steel, $4 \%$ zinc oxides and the final $10 \%$ consists of rayon, nylon, polyester, sulfur and other minor compounds.

At the beginning of each test, the reactor was filled with a specific mixture of inert and shredded tires. The mixture composition varied between 50\% to 100\% (by mass) shredded tires with the remaining amount consisting of the inert material. The lower limit was established by the presence of a self-propagating front. For tire fractions lower than $50 \%$ the reaction front was 
unstable and the results difficult to reproduce. In each case, the mass of the tires was $110 \mathrm{~kg}$ and the mass of the inert was varied in order to create the desired mixture. In order to initiate the combustion process, the airflow was set to its maximum value. The exhaust fan was started and the post combustion chamber flame was ignited. The torch at the base of the fuel bed was ignited which corresponds to time zero for the experiments. The torch was extinguished after 210 sec. The reaction in the fuel bed was self-sustaining at this point in time for all conditions tested.

The experiment was continued until the reactions ceased as indicated by the temperature measurements. The height of the fuel bed was determined by dropping a weighted stainless steel cable into the reactor and measuring the length when the weight contacted the fuel bed $(\mathrm{H})$. The mass of oil collected was measured at regular intervals during the experiment. The calorific output and chemical composition $\left(\mathrm{C}, \mathrm{H}, \mathrm{S}, \mathrm{N}, \mathrm{Cl}\right.$ and $\left.\mathrm{H}_{2} \mathrm{O}\right)$ of the recovered oil was established $a$ posteriori. Furthermore the chemical structure was established using Proton Nuclear Magnetic Resonance (RMN1H) and Gas Chromatography (GC). The residual mass in the reactor was measured at the end of the experiment.

\section{The Reaction Front}

The traces of a set of thermocouples placed along the reactor wall are shown in Fig. 2 for an experiment in which the fuel bed consisted of $50 \%$ tires and airflow of $20 \mathrm{~kg} / \mathrm{h}$. The ignition process dominates the initial temperature rise for thermocouples 1 and 2. The different slopes in the temperature profiles suggest a multistage process in which different mechanisms dominate. The initial reaction of the volatiles produces water that condenses downstream. The water then evaporates as the reaction front approaches. A plateau occurring between $60^{\circ} \mathrm{C}-80^{\circ} \mathrm{C}$ evidences this process. At the base of the fuel bed (thermocouple 1), there is no accumulation of water and 
so this process is hardly evident. Since the heat wave reaches the downstream locations at progressively later times, there is more time for water to accumulate. Hence, the plateau at $60^{\circ} \mathrm{C}$ is more pronounced at each downstream location. Similar plateaus have been previously reported for temperature histories corresponding to forward smolder of polyurethane foam [7].

After the water has been evaporated the temperature begins to rise as the combustion front approaches the thermocouple. The temperature rise is first slow but as the temperature reaches approximately $310^{\circ} \mathrm{C}$ there is a second plateau followed by a sudden increase in temperature (Thermocouple (3)). This plateau seems to correspond to a first endothermic pyrolysis reaction that increases in rate as the temperature rises from $60^{\circ} \mathrm{C}$ to $200^{\circ} \mathrm{C}$. Here the description of the temperature histories needs to be broken in two. An initial process can be established between thermocouples (1) and (4). For this region, once the fuel has undergone pyrolysis its temperature increases as the thermal front gets closer and finally is converted through strong exothermic oxidation. The process at this stage is transient. The temperatures seem to reach a maximum for thermocouple (3) and then slowly decay to what seems to be the steady condition. It is important to note that as time progresses the propagation velocity decreases. The decrease in propagation velocity is representative of higher fuel conversion and thus of a larger fraction of the incoming oxidizer consumed at the reaction front. This is clearly evidenced by the appearance of a second endothermic plateau at approximately $600^{\circ} \mathrm{C}$. This second plateau is not noticeable in the earlier stages of the process but acquires importance at the location of thermocouple (5). It is important to note that this process is occurring simultaneously to oxidation upstream. The presence of a low oxygen environment and the heat input from the oxidation seems to hamper oxidation at this level of the reactor. Thermocouple (6) reaches an almost constant temperature also at $600^{\circ} \mathrm{C}$. Between 12000 and 18000 seconds the temperature fluctuates around $600^{\circ} \mathrm{C}$. Then it stabilizes following a slightly increasing trend. 
Figure 2 also presents the location of the end of the fuel bed. As the reaction consumes the fuel, the fuel and inert bed collapses downwards and the top of the fuel bed descends. At 15000 seconds, thermocouple (5) starts an abrupt process of cooling. At this same time the top of the fuel bed seems to reach approximately $1050 \mathrm{~mm}$. This shows that the end of the fuel more or less coincides with the location of thermocouple (5). The differences lie clearly within the possible experimental error. Thus, the oxidation front has reached the end of the sample and extinction follows. A similar observation can be made for thermocouple (6) where the thermal front reaches the end of the sample at the same time as the onset of the $600^{\circ} \mathrm{C}$ plateau.

Thermocouples (7) and (8) show temperatures significantly lower than those representative of any combustion regime. Throughout most of the test both thermocouples remain outside the fuel bed.

To clarify the different stages of the process it is necessary to plot the temperature evolution as a function of the axial coordinate and for different times throughout the test. The data extracted from Figure 2 is presented in this format in Figure 3. This figure shows data only after the ignition period and the establishment of a self-sustained exothermic reaction ( $\mathrm{t}>1000 \mathrm{sec}$ ). By 1800 seconds the reaction is established at approximately $100 \mathrm{~mm}(\mathrm{H}=1900 \mathrm{~mm})$ from the grid and by $7200 \mathrm{sec}$ has progressed almost $500 \mathrm{~mm}(\mathrm{H}=1500 \mathrm{~mm})$. In this period the reaction increases in strength showing a consistent increase in the peak temperatures. A change in regime characterized by slower temperature decay in the region upstream of the reaction front occurs at this stage. This is probably due to energy generated from the further oxidation of the residue produced by the first reaction front. Oxidation upstream results in oxygen depletion and thus a weaker reaction temperature. This will not occur earlier because the incoming air will cool the residue hampering oxidation. As the front moves away from the air inlet, convective cooling is reduced and char oxidation acquires a stronger role. The reaction will continue to propagate 
until at approximately 14400 seconds it reaches the end of the fuel bed, as indicated by the hatched box. Beyond this time oxidation within the residue continues and the fuel bed descends further. Nevertheless temperatures begin to steadily decay.

Thermocouple (6), placed at $900 \mathrm{~mm}$ is outside that fuel bed according to the measurements of the bed height. There is some possibility, however, for nonuniformity in the bed height at varying radial locations and so these temperatures may still be representative of the fuel bed. This is important to point out because Figures 2 and 3 show some heat generation in this region. The temperatures are also characteristic of heterogeneous combustion.

Species concentrations are presented in Figure 4 and correspond to measurements made after condensing all liquid components as oils and passing through the afterburner. These pollutant concentrations are within international regulations. Furthermore, these measurements add further insight to the nature of the reaction. Figure 4 shows that the oxygen concentration starts to increase as the reaction front reaches the end of the fuel bed, nevertheless oxygen concentrations do not progress beyond $13 \%$. In contrast, NOx concentrations decay as the main reaction front reaches the end of the bed. NOx originates mostly from the fuel and oxygen could be depleted within the fuel bed or through combustion of the products emerging from the reactor. Therefore, this information is indicative of a significant reduction of the combustion products after the main reaction front has quenched. Furthermore, the low levels of oxygen imply that heterogeneous combustion is still progressing within the reactor. In the absence of any fuel degradation, oxygen concentrations would be much higher. Carbon monoxide concentrations are negligible throughout most of the test and increase only towards the end of the experiment. SOx follow very similar trends. A sudden increase in CO and SOx is evident after 18000 seconds. This increase occurs after turning off the afterburner and shows the magnitude of the combustion 
products emerging from the reactor. Again this indicates that combustion is still progressing in the reactor.

\section{Fuel Consumption and Oil Recovery}

As the reaction front propagates, cooling of the combustion products results in the collection of condensed hydrocarbons. This is an important part of this process because it allows recovering a significant fraction of the fuel. The molecular composition of the oil was determined as being mostly carbon (86.12\%), hydrogen (11.95\%), water (0.36\%), nitrogen (0.31\%), sulfur (1.24\%) and chlorine $(0.02 \%)$ mainly grouped as aliphatiques, aromatics and ethylenes. The integrity of the vulcanization zinc present in the tires is recovered with the oil. The calorific output of this oil is of the order of $40-43 \mathrm{~J} / \mathrm{kg}$, thus it could be potentially used as a fuel. In this section, the different reaction parameters affecting the recovery of oil will be presented.

The evolution of the mass loss is tracked best in the absence of inert material, therefore the results for the variation of " $\mathrm{H}$ " with time correspond to $100 \%$ tires (Figure 5). From the figure it can be observed that $\mathrm{H}$ increases with time in an almost linear fashion. An increase in airflow rate results in an increase in the mass consumption rate ( $\mathrm{H}$ increases faster) evidencing an oxygen-limited process. Once complete consumption is achieved " $\mathrm{H}$ ” does not vary anymore. As expected, the larger the flow rate the faster total consumption is achieved.

In contrast to the clearly defined trends observed for the evolution of " $\mathrm{H}$ " the quantity of recovered oil follows a much more complex evolution. The production of oil as a function of time is presented in Figure 6 for the same conditions as those corresponding to Figure 5. It can be observed that the production of oil increases with time and the time scales match well those presented in Figure 5. An increase in flow velocity results in an acceleration of the process. Initially, the final quantity of oil seems to increase slightly with the airflow but a significant 
increase of the oil fraction is observed for $35 \mathrm{~kg} / \mathrm{h}$. This increase seems to mark a dramatic change in regime that will hamper the production of oil very early on in the combustion process at higher flow rates. This change in regime seems to correspond to a more complete combustion process or a departure from an oxygen-limited process.

Figure 7 shows the evolution of the propagation velocity, the total oil recovery and the final mass of residue as a function of the airflow (residue and oil recovery expressed in percentages from the total fuel mass). All data presented corresponds to $100 \%$ tires. Figure 7 clearly shows the two regimes mentioned above. Initially an increase in airflow will lead to a decrease in the propagation velocity. Again this is typical of a highly energetic oxygen limited reaction in which an extra supply of oxygen leads to a higher conversion of fuel. The amount of residue remains almost invariant within this regime, therefore the conversion rates are simply associated with the fraction of fuel that is oxidized while the rest of the fuel is pyrolyzed into the hydrocarbons that were collected as oils. Increase in conversion rates can be associated with a decrease in the propagation velocity if the reaction rate is the controlling mechanism for propagation. A critical condition seems to be reached around $35 \mathrm{~kg} / \mathrm{h}$ of air where oil production is a maximum and propagation velocities reach a minimum. For larger airflows the propagation velocity increases dramatically. Conversion increases, since the residue drops significantly, but the mass of oil also decreases denoting a more vigorous oxidation.

An equally evident transition process is observed when changing the fraction of tires and keeping the airflow rate constant. Figure 8 shows the evolution of " $\mathrm{H}$ " for $30 \mathrm{~kg} / \mathrm{h}$ and different tire fractions. For $50 \%$ tire fraction " $\mathrm{H}$ " increases linearly with time until the reaction ceases to propagate. It is important to note that there is no slow decay in the evolution of " $\mathrm{H}$ " indicating that the reaction quenched without complete consumption of the fuel. An increase in the percentage of fuel results in a more stable reaction where " $\mathrm{H}$ " increases faster and eventually 
slows down towards complete consumption of the fuel. For a tire fraction greater than $70 \%$ " $\mathrm{H}$ " increases at a much slower pace initially followed by a rapid transition that leads to complete consumption of the fuel. Within this regime the percentage of tires seems to have only a weak effect on the evolution of "H." It is interesting to note that the maximum temperature is relatively constant for all conditions (Fig. 9).

This regime change is more difficult to explain since an increase in the mass fraction of tires should lead to an increase in the volumetric energy release rate and therefore result in an enhanced mass conversion and higher temperatures. A simple accounting of the energy is necessary to explain this change in regime. In general radiation is more important than conduction, thus for this simple analysis conduction terms will be neglected. Assuming a frame of reference anchored to the reaction front, thermal equilibrium between gas and solid phases and quasi-steady conditions, the net heat flux through the reaction front $(\Phi)$ is described by:

$\Phi=\varepsilon C p_{g} \rho_{g}\left(v_{g}-U_{F}\right) T_{F}-\left[\varepsilon C p_{g} \rho_{g}+(1-\varepsilon) C p_{s} \rho_{s}\right] U_{F} T_{F}$

Where $\varepsilon$ is the porosity (or void fraction), $\rho$ the density, Cp the specific heat, $\mathrm{v}$ the oxidizer flow velocity, $U_{F}$ the propagation velocity, $T_{F}$ the reaction front temperature and the sub-indices " $g$ " and "s" stand for gas and solid respectively. The assumption of thermal equilibrium between the gas and solid phases is justified for cases in which the heat transfer coefficient is high. This is true for a large class of problems and so is justified for this simplified analysis [6-9].

The first term to the right of equation (1) represents the energy convected by the flow towards the virgin materials while the negative term is the energy required to heat up the solid and gas moving towards the front at the propagation rate. For propagation to occur $\Phi$ has to take a positive value. Scaling equation (1) by the energy required to heat the solid and gas we obtain: 


$$
\bar{\Phi}=\frac{\Phi}{\left[\varepsilon C p_{g} \rho_{g}+(1-\varepsilon) C p_{s} \rho_{s}\right] U_{F} T_{F}}=\Delta-1
$$

Where

$$
\Delta=\frac{\varepsilon \mathrm{Cp}_{\mathrm{g}} \rho_{\mathrm{g}}\left(\mathrm{v}_{\mathrm{g}}-\mathrm{U}_{\mathrm{F}}\right)}{\left[\varepsilon \mathrm{Cp}_{\mathrm{g}} \rho_{\mathrm{g}}+(1-\varepsilon) \mathrm{Cp}_{\mathrm{s}} \rho_{\mathrm{s}}\right] \mathrm{U}_{\mathrm{F}}} \approx \frac{\varepsilon \mathrm{Cp}_{\mathrm{g}} \rho_{\mathrm{g}}\left(\mathrm{v}_{\mathrm{g}}\right)}{\left[(1-\varepsilon) \mathrm{Cp}_{\mathrm{s}} \rho_{\mathrm{s}}\right] \mathrm{U}_{\mathrm{F}}}
$$

If the conditions $\mathrm{v}_{\mathrm{g}}>\mathrm{U}_{\mathrm{F}}$ and $\rho_{\mathrm{s}} \mathrm{Cp}_{\mathrm{s}}>>\rho_{\mathrm{g}} \mathrm{Cp}_{\mathrm{g}}$ can be demonstrated. Introduction of characteristic values for these experiments show that the simplification of $\Delta$ is appropriate for the present conditions.

It is important to note that the value of $\Delta$ is not a function of the energy release rate, but only of the heat capacities of the solid and gas. If $\Delta>1$ heat is transferred downstream of the reaction in quantities greater than what is necessary for propagation. This leads to accelerated propagation of the front that will occur due to the cumulative preheating of the fuel. $\Delta<1$ implies that the solid and gas do not receive enough energy to reach the reaction front temperature $\left(T_{F}\right)$, thus propagation will decelerate. The case $\Delta=1$, generally termed superadiabatic combustion [8,9], implies that the front and heat wave progress at the same speed, thus all the energy accumulates at the reaction front. It can be further shown that the reaction front temperature is given by $\mathrm{T}_{\mathrm{F}}=\mathrm{T}_{\text {adiabaic }} / \Delta-1 \mid[9]$ which indicated that for $\Delta=1$ there is a temperature runaway that is only limited by losses not included in the present analysis.

The value of $\Delta$ was evaluated for conditions that correspond to both regimes. The case presented in Figures 2 and 3 corresponded to the left of the inflection point (Figure 9) and for the regime to the right a flow velocity of $20 \mathrm{~kg} / \mathrm{h}$ and $80 \%$ tires was used. The former case leads to a 
value of $\Delta=0.4$ and the latter $\Delta=0.05$. Gas properties were assumed to be those of air at $1300^{\circ} \mathrm{C}$ and the porosity $61 \%$. The propagation velocities were calculated from the temperature histories.

Figure 10 shows the evolution of the temperature along the fuel bed for conditions where $\Delta=0.05$. It can be clearly noticed that the propagation rates are very small and all the energy concentrates behind the reaction front. Comparison with Figure $3(\Delta=0.4)$ shows an entirely different behavior. Here heat is transported downstream of the reaction front enabling propagation of the reaction through the bed. It is important to note that within both regimes super-adiabatic combustion could be achieved, nevertheless, during the present experiments this condition was not attained. The experimental observations and the differences between the values of $\Delta$ seem to indicate that this analysis can provide a qualitative explanation to the presence of the two regimes. Nevertheless, quantitatively, the present thermal analysis is limited by the different chemical processes that will have a significant effect on $U_{F}$. Thus, it is not surprising that $\Delta$ appears always to be smaller than unity. Furthermore, tuning the process to achieve super-adiabatic combustion will require a much more detailed understanding of the degradation pathways of the fuel.

\section{Conclusions}

An upward burning forward combustion reaction has been allowed to propagate through a porous media consisting of shredded tires and refractory briquettes. Temperature measurements, propagation velocities and volume reduction have been measured. The combustion products have been cooled down and the condensate has been recovered. The following conclusions have been reached:

The combustion process is influenced by the airflow rate through the reactor. An oxygen limit combustion reaction transitions from a rate-limited regime to a heat transfer-limited regime. 
The transition follows an increase in airflow. The rate-limited regime is characterized by high production of residual oil and low propagation velocities. The heat transfer limited regime reduces the production of oil but results in a much faster conversion of the fuel.

A self-sustained reaction can only be achieved with a mass fraction of tires that exceeds $50 \%$.

Two different regimes are also observed as a function of the mass fraction of tires. For mass fractions of tires less than $70 \%$ conversion rates and temperatures are proportional to the mass fraction of tires. In this regime the volumetric energy density dominates the combustion process. For a mass fraction of tires greater than $70 \%$ the conversion rate is independent of the amount of fuel and it is initially much slower than for lower fuel concentrations. These two regimes can be described in a qualitative manner by a simple energy balance.

This study has evidenced a promising methodology to convert discarded tires into a usable fuel while reducing significantly the mass of residue.

\section{References}

[1] A.D.E.M.E., La Collecte et le Traitement des Déchets, A.D.E.M.E. Report, 1996.

[2] Koshland C., Proc. Comb. Inst., 26:2049-2065 (1996).

[3] Napoli, A., Pyrolyse d'un Déchet Carboné en Vue de sa Valorisation: Application aux Pneumatiques Usagés, PhD Thesis, Université Paul Sabatier de Toulouse, 1998.

[4] Société SOLEN Environnement \& Logistique, Méthode d'Evaluation et d'Optimisation Economique et Environnementale des Filières de Pneumatiques Usagés, A.D.E.M.E. Report, Angers, 1996.

[5] Roy,C. Labrecque, B. and De Caumia, B., Res. Conserv. Recy., 4:203-213 (1990).

[6] Ohlemiller, T. J., Prog. Energy Combust. Sci., 11:277-310 (1985).

[7] Torero, J.L. and Fernandez-Pello, A.C. Combustion and Flame, 106 (1-2), 89-109, (1996).

[8] Merzhanov, A.G. and Khaikin, B.I., Prog. Energy Combust. Sci., 14, 1-98 (1988).

[9] Aldushin, A.P., Rumanov, I.E. and Matkowski, B.J., Combustion and Flame, 118, 76-90, 1999. 


\section{Figure Captions}

Figure 1. Schematic of the experimental facility.

Figure 2. Temperature histories for a $50 \%$ tire experiment and $20 \mathrm{~kg} / \mathrm{h}$ flow rate. The position of each thermocouple is measured from the top of the reactor. The evolution of the charge height $(\mathrm{H})$ as a function of time is also presented.

Figure 3. Evolution of the temperature along the axial direction. The data corresponds to a $50 \%$ tire and $20 \mathrm{~kg} / \mathrm{h}$ test. Hatched boxes illustrate the location of the top of the fuel bed and its regression with time. The ignition grid is at the left of the plot $(\mathrm{H}=2000)$.

Figure 4 Concentrations of different combustion products measured. The black line shows the time when the combustion front reaches the end of the fuel bed.

Figure 5. Evolution of the fuel level as a function of time for $100 \%$ tires.

Figure 6. Evolution of the percentage of the total fuel recovered as oil. The data presented is the summation of all collected quantities.

Figure 7. Evolution of the propagation velocity, oil recovered and residue as a function of the airflow rate for $100 \%$ tires.

Figure 8. Evolution of the fuel height with time as a function of the tire mass fraction. All experiments correspond to an airflow of $30 \mathrm{~kg} / \mathrm{h}$.

Figure 9. Evolution of the maximum-recorded temperature as a function of the tire mass fraction. All data corresponds to an airflow of $30 \mathrm{~kg} / \mathrm{h}$

Figure 10. Evolution of the temperature along the axial direction. The data corresponds to a $80 \%$ tire and $20 \mathrm{~kg} / \mathrm{h}$ test. The ignition grid will be placed at the left of the plot $(\mathrm{H}=2000)$ 
Figure 1. Schematic of the experimental facility.

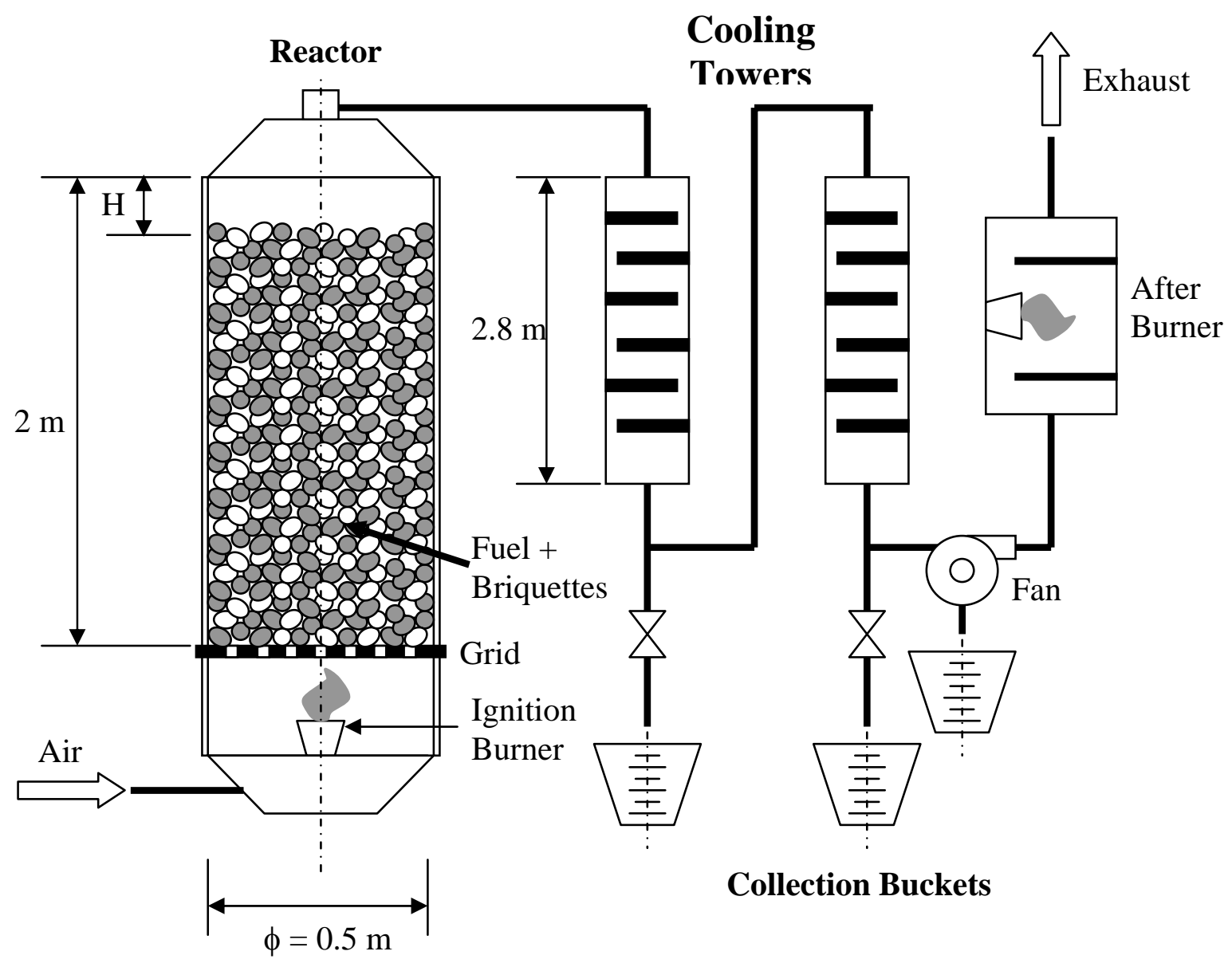

Figure 2. Temperature histories for a $50 \%$ tire experiment and $20 \mathrm{~kg} / \mathrm{h}$ flow rate. The position of each thermocouple is measured from the top of the reactor. The evolution of the charge height $(\mathrm{H})$ as a function of time is also presented.

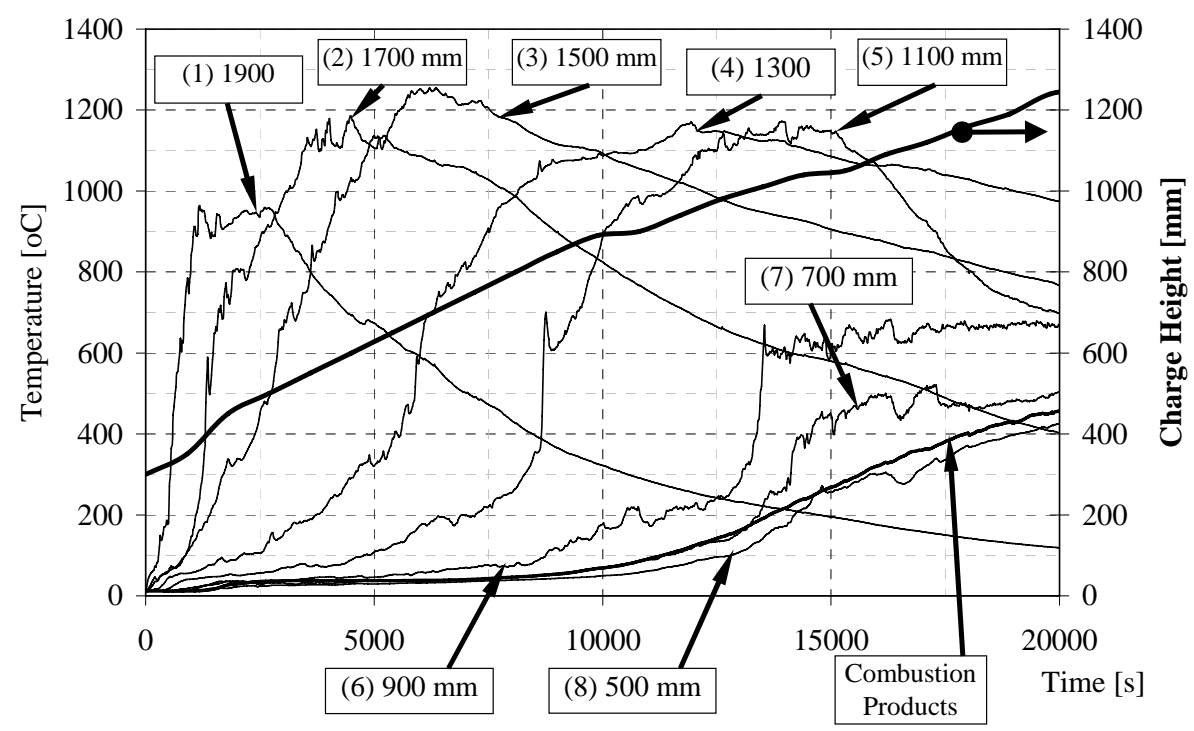


Figure 3. Evolution of the temperature along the axial direction. The data corresponds to a $50 \%$ tire and $20 \mathrm{~kg} / \mathrm{h}$ test. Hatched boxes illustrate the location of the top of the fuel bed and its regression with time. The ignition grid is at the left of the plot $(\mathrm{H}=2000)$

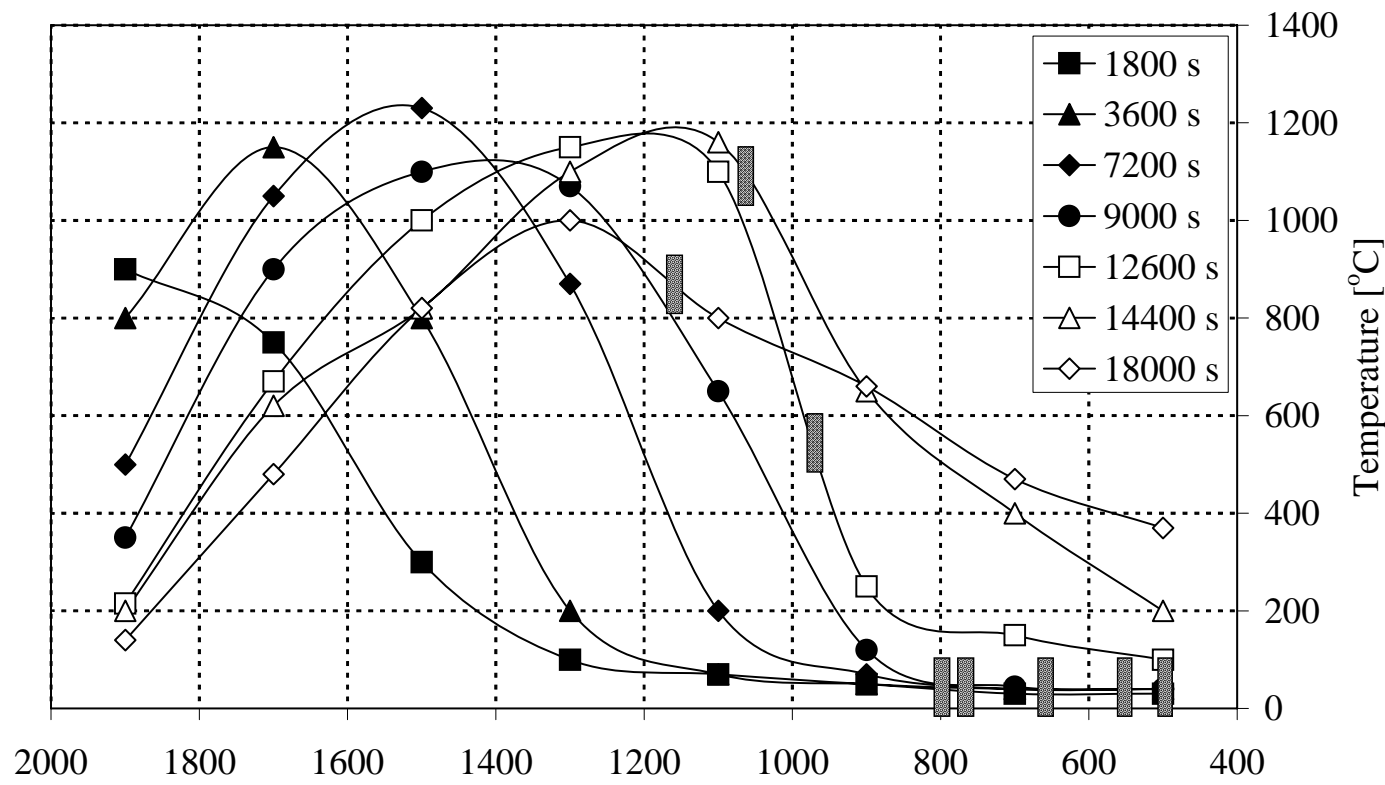

Distance from the top of the Chamber [mm]

Figure 4 Concentrations of different combustion products measured. The black line shows the time when the combustion front reaches the end of the fuel bed.

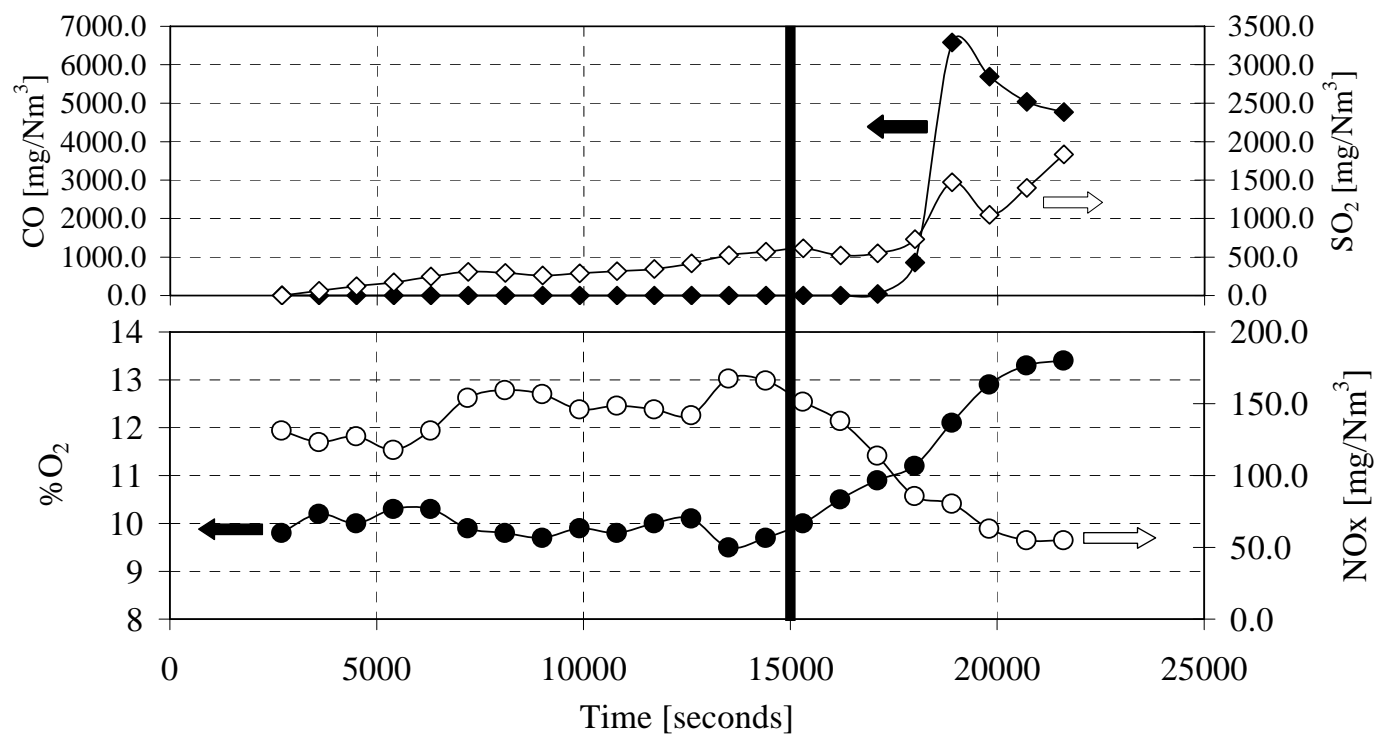


Figure 5. Evolution of the fuel level as a function of time for $100 \%$ tires.

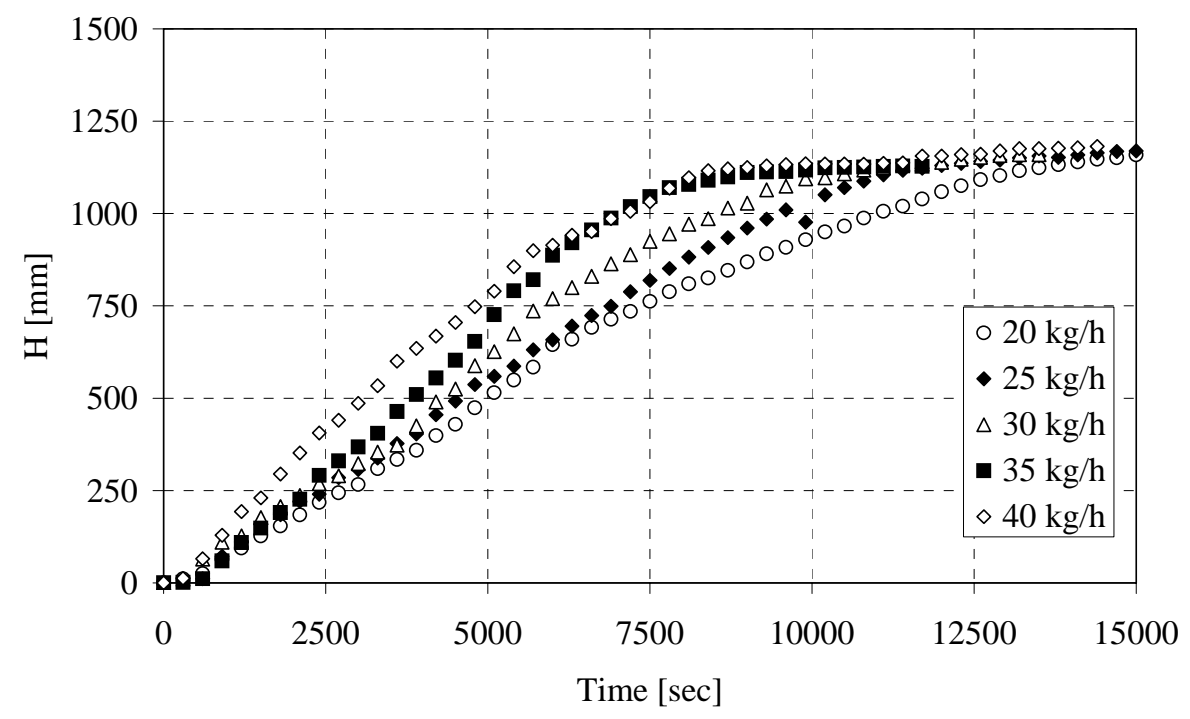

Figure 6. Evolution of the percentage of the total fuel recovered as oil. The data presented is the summation of all collected quantities.

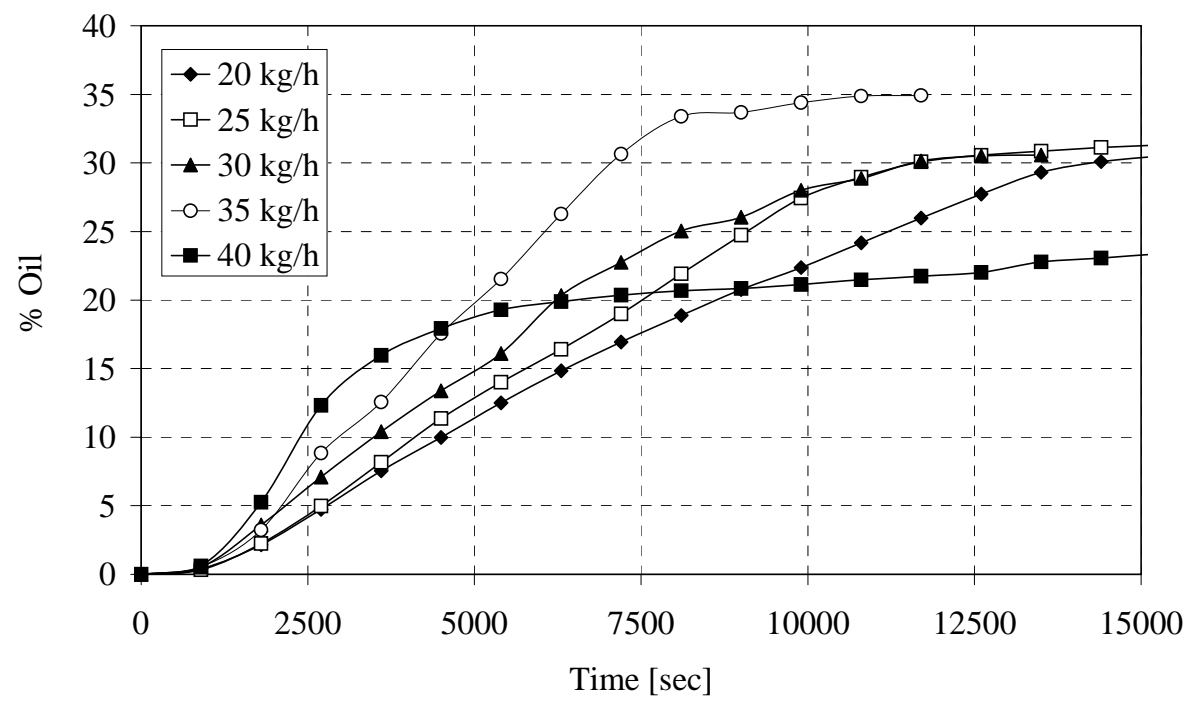


Figure 7. Evolution of the propagation velocity, oil recovered and residue as a function of the airflow rate for $100 \%$ tires.

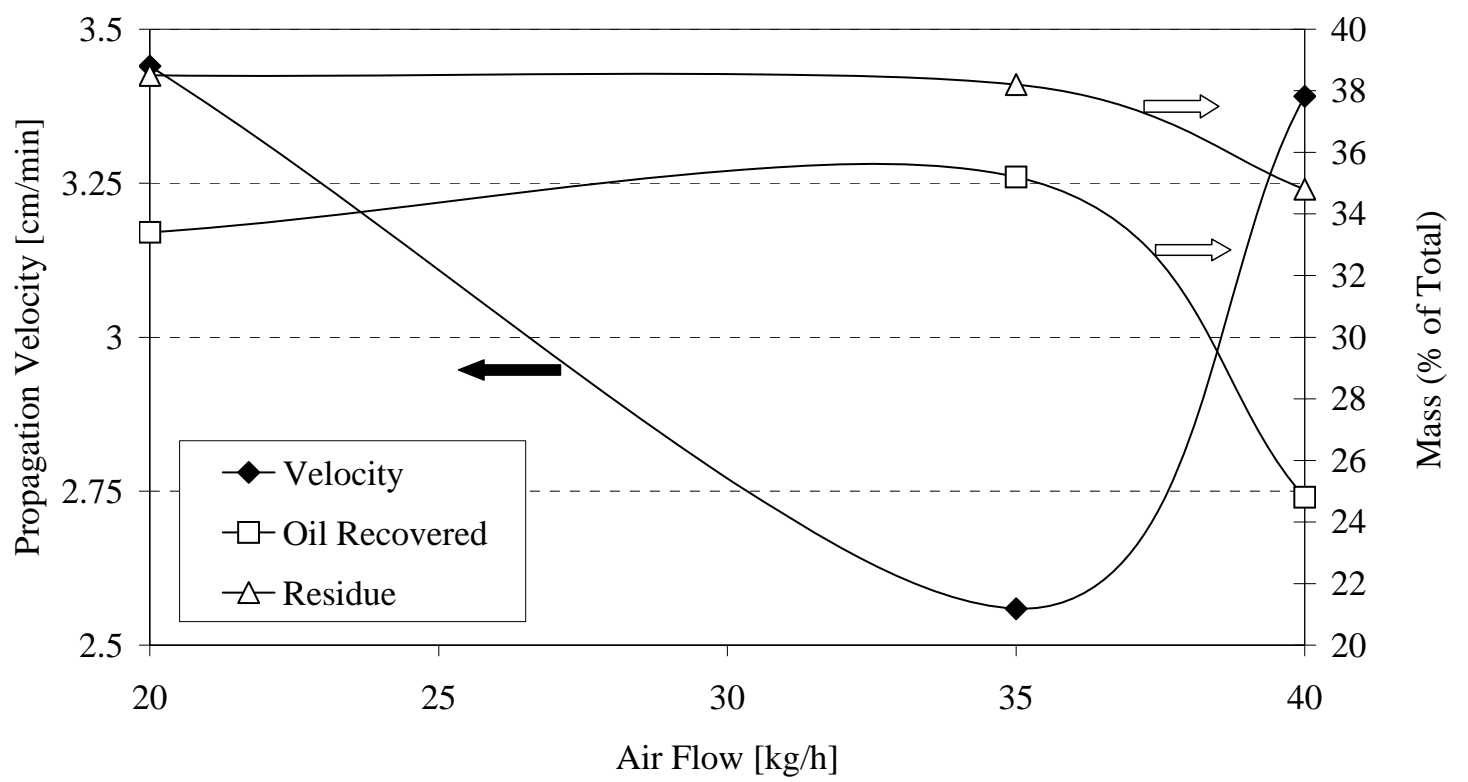

Figure 8. Evolution of the fuel height with time as a function of the tire mass fraction. All experiments correspond to an airflow of $30 \mathrm{~kg} / \mathrm{h}$.

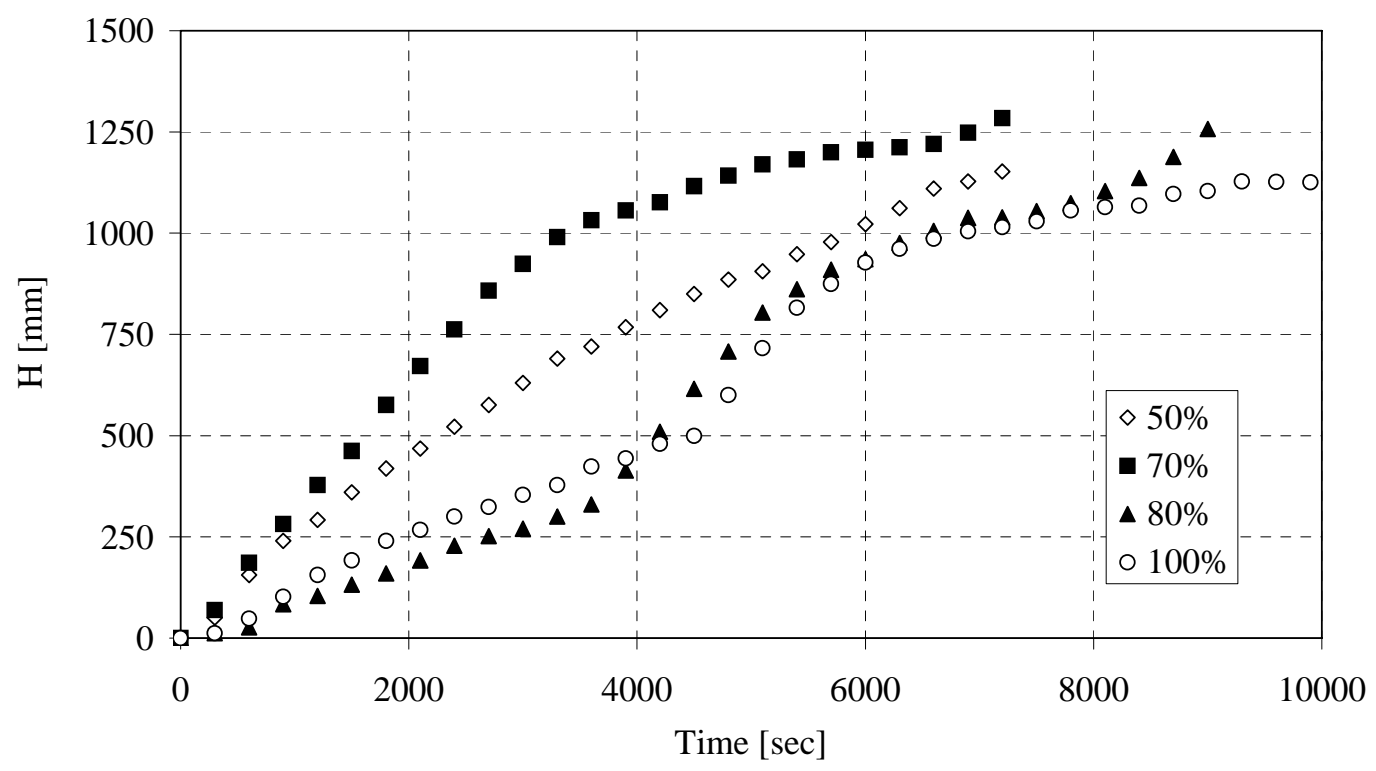


Figure 9. Evolution of the maximum-recorded temperature as a function of the tire mass fraction. All data corresponds to an airflow of $30 \mathrm{~kg} / \mathrm{h}$

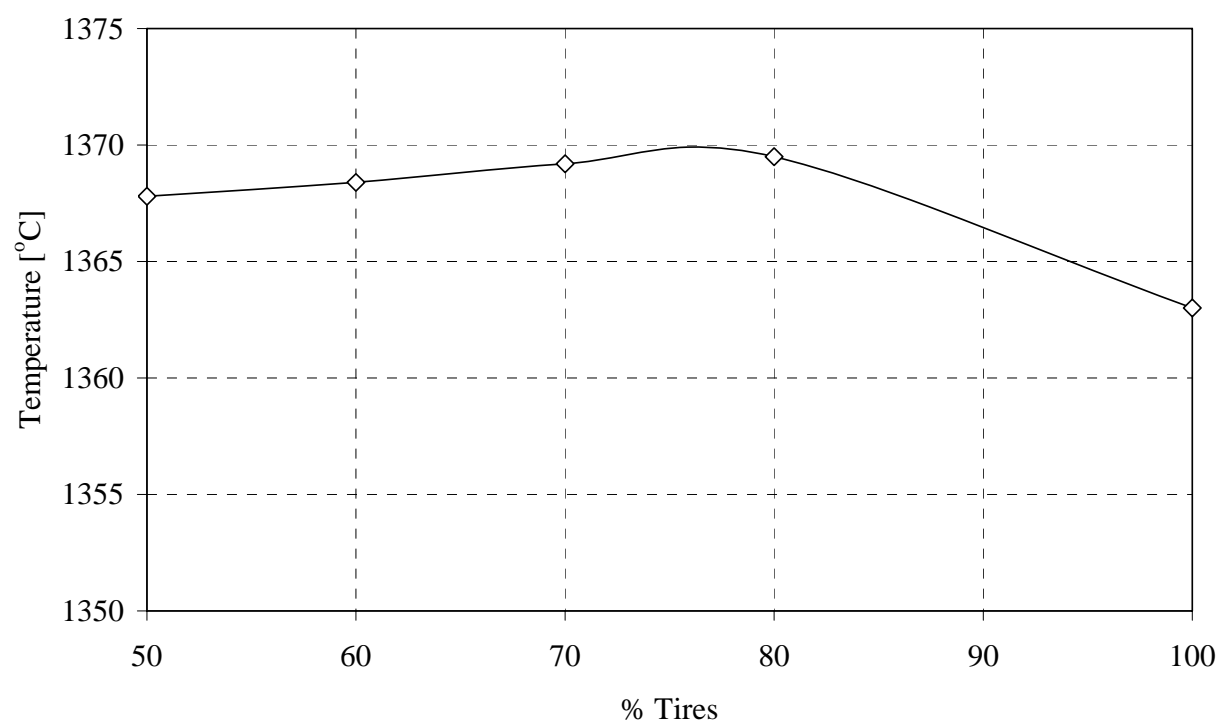

Figure 10. Evolution of the temperature along the axial direction. The data corresponds to a $80 \%$ tire and $20 \mathrm{~kg} / \mathrm{h}$ test. The ignition grid will be placed at the left of the plot $(\mathrm{H}=2000)$

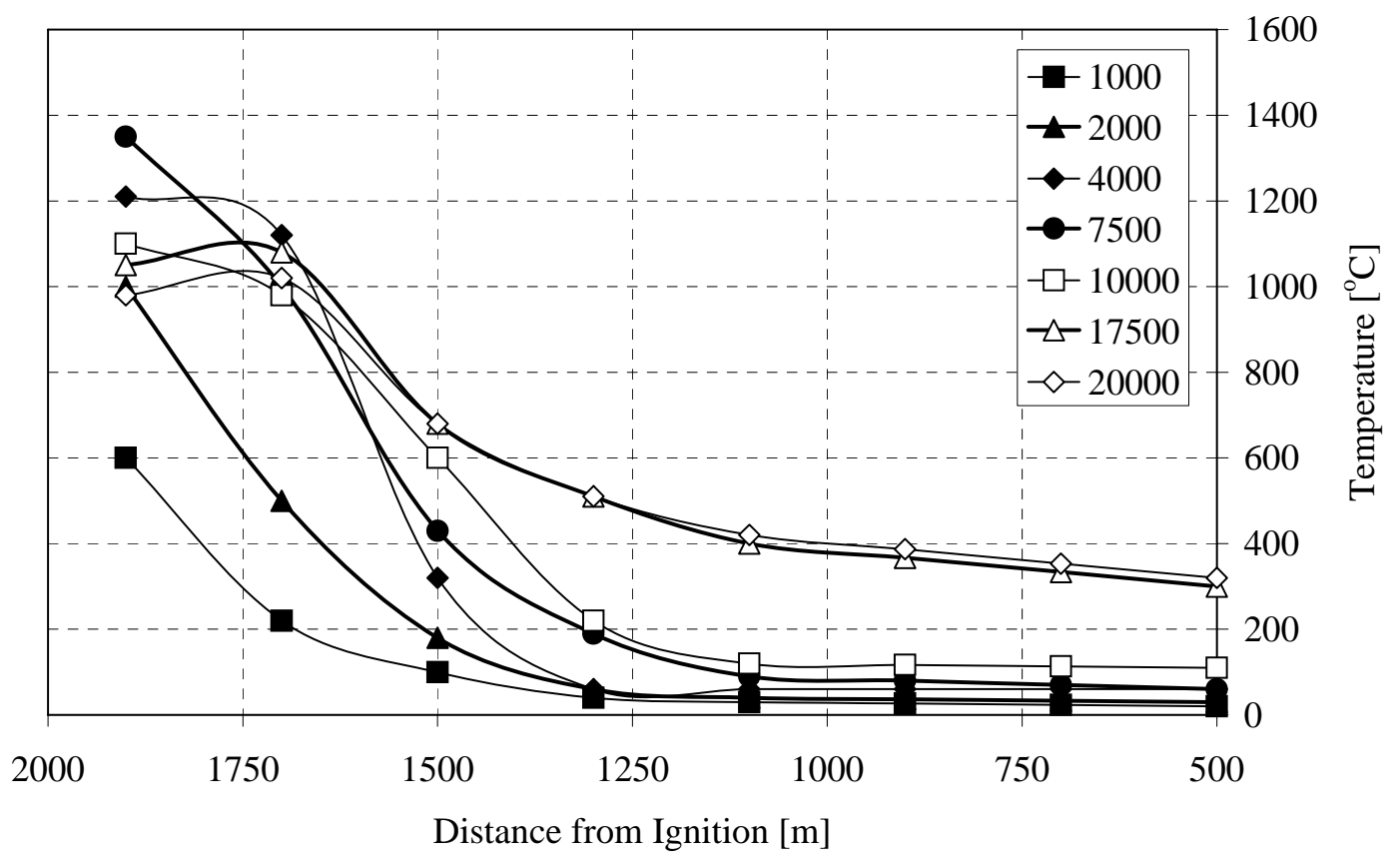

